\title{
Rising Mortality From Alcohol-Associated Liver Disease in the United States in the 21st Century
}

Andrew M. Moon, MD, MPH ${ }^{1}$, JeffY. Yang, BS ${ }^{2}$, A. Sidney Barritt IV, MD, MSCR ${ }^{1}$, Ramon Bataller, MD, $\mathrm{PhD}^{3}$ and Anne F. Peery, MD, MSCR ${ }^{1}$

OBJECTIVES: In contrast with other developed nations, life expectancy is decreasing in the United States, in part due to increasing mortality from alcohol-associated liver disease (ALD). Up-to-date estimates of ALD mortality are necessary for setting public health priorities to reverse this concerning trend. We therefore aimed to assess current (2017) estimates of ALD mortality and temporal trends from 1999 to 2017.

METHODS: $\quad$ Using national data from the Centers for Disease Control and Prevention, we analyzed stratified ALD mortality rates between 1999 and 2017. We determined the age-adjusted death rates, stratified by sex and categorized by age, race/ethnicity, urbanization, and census region. We also identified statistically significant changes in the annual rate difference (ARD), annual percentage change (APC), and average APC in ALD mortality.

RESULTS: $\quad$ In 2017, mortality from ALD was higher than any other year since 1999 with age-adjusted rates of 13.1 per $100,000(95 \%$ confidence interval [Cl] 12.9-13.3) in men and 5.6 per 100,000 (95\% Cl 5.4-5.7) in women. Mortality was highest among men and women who were middle aged, Native American, and from rural areas. Since 2006, ALD mortality has increased in almost every age group and race with the exception of non-Hispanic black men. Absolute increases in mortality rates have been particularly pronounced in Native American women (2005-2017 ARD 0.8, 95\% Cl 0.6-0.9), non-Hispanic/white men (2006-2017 ARD 0.4, 95\% Cl 0.3-0.4), and non-Hispanic/white women (2013-2017 ARD 0.4, 95\% Cl 0.3-0.5).

DISCUSSION: Mortality from ALD is increasing over time in most demographic groups. Increased effort is needed to develop targeted public health strategies to address high and increasing ALD mortality.

SUPPLEMENTARY MATERIAL accompanies this paper at http://links.Iww.com/AJG/B305, http://links.Iww.com/AJG/B306

Am J Gastroenterol 2020;115:79-87. https://doi.org/10.14309/ajg.0000000000000442

\section{INTRODUCTION}

In 2017, the life expectancy of Americans decreased, running counter to trends in the rest of the developed world (1). Although overshadowed by the opioid epidemic, alcohol-associated liver disease (ALD) has been identified as a contributing factor in decreasing life expectancies, particularly among non-Hispanic whites (2). Furthermore, health care expenditures for alcohol use disorder (AUD) are estimated at $\$ 9$ billion dollars annually, ALD accounts for more inpatient health care costs than all other etiologies of cirrhosis combined, and ALD is now the leading indication for liver transplantation (3-5).

Despite its considerable burden, ALD remains relatively understudied and underfunded, possibly as a result of its social stigma (6). The gap between the substantial burden of ALD and the attention it garners underscores the importance of accurate and up-to-date mortality estimates of ALD in the United States. Previous publications found an increase in ALD mortality, but these analyses did not stratify by sex or disaggregate mortality by age and race $(7,8)$. In addition, a recent study on mortality from cirrhosis and hepatocellular carcinoma in the United States focused on the relative changes in ALD mortality (8). An in-depth assessment of current mortality rates from ALD, including a focus on the absolute changes in ALD mortality rates, and differences in ALD mortality by age, sex, and race/ethnicity are essential to develop targeted public health strategies.

To characterize the burden of ALD, we had 2 aims. First, we evaluated the current (2017) estimates of ALD mortality stratified by sex and subcategorized by age, race/ethnicity, urbanization, and region. Second, we assessed temporal trends in ALD mortality within these subgroups between 1999 and 2017.

\section{METHODS}

Using the Centers for Disease Control and Prevention Underlying Cause of Death database, we analyzed ALD mortality 
rates from 1999 to 2017 (9). This database is maintained by the National Center for Health Statistics (NCHS) and contains mortality and population counts for all US counties. Data are based on death certificates, each of which identifies a single underlying cause of death selected from the conditions entered by a physician. When more than 1 cause or condition is entered by the physician, the underlying cause is determined by the sequence of conditions on the death certificate, rules of the International Classification of Diseases (ICD) system, and associated selection guidelines and modifications.

We included all patients with ALD (K70) listed as the underlying cause of death, as identified by its corresponding ICD, 10th Revision, Clinical Modification code (ICD-10). We excluded patients younger than 25 years because the number of deaths among individuals younger than 25 is too small to produce reliable estimates of mortality rates.

We stratified by sex and reported mortality overall and by 10 year age groups, race/ethnicity, urbanization, and census region. Census regions are classified as Northeast, Midwest, South, and West according to the state of residence at the time of death (https:// wonder.cdc.gov/wonder/help/ucd.html\#Census\%20Regions).

Age adjustment was performed using methods proposed by the NCHS and was based on age distributions from the 2000 US census (10). Race/ethnicity was classified as white/non-Hispanic, black/ non-Hispanic, Hispanic, and Native American. We included both
Hispanic and non-Hispanic ethnicities within the Native American subgroup. For urbanization, we used the 2013 NCHS Urban-Rural Classification Scheme for Counties. Large central metro, large fringe metro, medium metro, and small metro were considered urban, whereas micropolitan and noncore were classified as rural.

We assessed changes in annual mortality rate trends on both the absolute scale (annual rate difference [ARD]) and relative scale (annual percentage change [APC] and average APC), using the National Cancer Institute's Joinpoint program (version 4.7.0.0, http://surveillance.cancer.gov/joinpoint). This methodology for examining trends in mortality data has been recommended by the National Cancer Institute and has been used in previous publications $(8,11-16)$. The Joinpoint program is able to fit data on trends (e.g., ALD mortality over time) into a model that identifies statistically significant changes in trends (i.e., joinpoints). Additional information on the underlying methodology is included in Supplementary Material (see Supplementary Digital Content 1, http://links.lww.com/ AJG/B305).

Based on the joinpoints produced in the final models, we estimated ARD, APC, and average APC for the observed data, overall and within each subgroup. SEs and 95\% confidence intervals (CIs) were estimated using Monte Carlo simulation with 4,500 iterations.

Table 1. Crude and age-adjusted mortality from ALD in women, 2017

\begin{tabular}{|c|c|c|c|}
\hline & Deaths & $\begin{array}{l}\text { Crude mortality } / 100,000 \text { population } \\
\qquad(95 \% \mathrm{Cl})\end{array}$ & $\begin{array}{l}\text { Age-adjusted mortality/100,000 population } \\
\qquad(95 \% \mathrm{CI})\end{array}$ \\
\hline Overall & 6,773 & $5.92(5.78-6.06)$ & $5.58(5.44-5.72)$ \\
\hline \multicolumn{4}{|l|}{ Age groups (y) } \\
\hline $25-34$ & 293 & $1.31(1.16-1.46)$ & - \\
\hline $35-44$ & 831 & 4.05 (3.78-4.33) & - \\
\hline $45-54$ & 1,975 & $9.20(8.79-9.61)$ & - \\
\hline $55-64$ & 2,376 & 10.93 (10.49-11.37) & - \\
\hline $65-74$ & 974 & $6.16(5.78-6.55)$ & - \\
\hline $75-84$ & 256 & $3.08(2.71-3.46)$ & - \\
\hline $85+$ & 68 & $1.62(1.26-2.06)$ & - \\
\hline \multicolumn{4}{|l|}{ Race/ethnicity } \\
\hline White/non-Hispanic & 5,095 & $6.81(6.62-7.00)$ & $6.34(6.15-6.52)$ \\
\hline Black/non-Hispanic & 573 & $3.98(3.65-4.30)$ & $3.74(3.43-4.05)$ \\
\hline Hispanic & 684 & 4.08 (3.77-4.38) & $4.23(3.91-4.55)$ \\
\hline Native American & 344 & $24.68(22.08-27.29)$ & $24.48(21.85-27.10)$ \\
\hline \multicolumn{4}{|l|}{ Urbanization } \\
\hline Urban & 5,668 & $5.77(5.62-5.92)$ & $5.44(5.29-5.58)$ \\
\hline Rural & 1,105 & $6.87(6.46-7.27)$ & $6.54(6.13-6.95)$ \\
\hline \multicolumn{4}{|l|}{ Region } \\
\hline Northeast & 823 & $4.00(3.73-4.27)$ & $3.77(3.50-4.04)$ \\
\hline Midwest & 1,361 & $5.73(5.43-6.03)$ & $5.42(5.12-5.72)$ \\
\hline South & 2,099 & $4.83(4.62-5.03)$ & $4.53(4.33-4.73)$ \\
\hline West & 2,490 & 9.38 (9.01-9.75) & $8.89(8.53-9.25)$ \\
\hline
\end{tabular}




\section{RESULTS}

\section{High ALD mortality in men and increasing mortality rates in both sexes}

In 2017, the age-adjusted ALD mortality was 5.6 per 100,000 (95\% CI 5.4-5.7) among all women and 13.1 per 100,000 (95\% CI 12.9-13.3) in men (Tables 1 and 2). For both sexes, these were the highest annual mortality rates of any year between 1999 and 2017. Among women, ALD mortality was stable between 1999 and 2006 (ARD 0.0, 95\% CI 0.0-0.0) but increased significantly between 2006 and 2013 (ARD 0.2, 95\% CI 0.1-0.2) and again between 2013 and 2017 by 0.3 per 100,000 annually (95\% CI 0.2-0.4) (Figure 1 and Table 3). Among men, mortality from ALD decreased between 1999 and 2006 by 0.1 per 100,000 annually (95\% CI -0.2 to 0.0 ) (Figure 1 and Table 4). Thereafter, ALD mortality rates in men increased significantly by 0.3 per 100,000 annually (95\% CI 0.3-0.4) from 2006 to 2017.

\section{Increases in ALD highest in middle-aged individuals}

In both men and women, ALD mortality was highest among those aged 55-64 years (Figure 2). In this age group, the 2017 crude mortality rate was 10.9 per 100,000 (95\% CI $10.5-11.4)$ for women and 28.4 per 100,000 (95\% CI 27.7-29.1) for men. Women of all ages had statistically significant increases in ALD mortality in recent years. The largest increase was seen in women aged 55-64 years with an annual 0.6 per 100,000 increase (95\% CI 0.5-0.6) from 2008 to 2017. From 1999 to the mid-2000s, ALD mortality in men remained flat or decreased in every age group. This trend has reversed in the last decade, with significant increases in mortality in men of all age groups and the largest increases in age 65-74 years from 2012 to 2017 (ARD 1.1, 95\% CI 0.8-1.4) and age 55-64 years from 2004 to 2017 (ARD 0.9, 95\% CI $0.8-0.9)$.

\section{ALD mortality increases highest in Native Americans and non- Hispanic whites}

In 2017, age-adjusted ALD mortality was highest among Native American men (34.1/100,000, 95\% CI 31.0-37.2) and women (24.5/100,000, 95\% CI 21.9-27.1) followed by Hispanic men (19.0/100,000, 95\% CI 18.3-19.8) and white/non-Hispanic men (13.2/100,000, 95\% CI 12.9-13.5). Mortality was comparatively lower among black/non-Hispanic women (3.7/100,000, 95\% CI 3.4-4.1) and men (8.3/100,000, 95\% CI 7.8-8.8).

In women, the largest increase in ALD mortality was seen in Native Americans with an ARD of 0.8 (95\% CI 0.6-0.9) from 2005 to 2017 (Figure 3). White/non-Hispanic women also have steady increases in ALD mortality since 1999, with the largest increases in more recent years (2013-2017 ARD 0.4, 95\% CI $0.3-0.5)$.

Table 2. Crude and age-adjusted mortality from ALD in men, 2017

\begin{tabular}{|c|c|c|c|}
\hline & Deaths & $\begin{array}{l}\text { Crude mortality/100,000 population } \\
\qquad(95 \% \mathrm{Cl})\end{array}$ & $\begin{array}{l}\text { Age-adjusted mortality/100,000 population } \\
\qquad(95 \% \mathrm{Cl})\end{array}$ \\
\hline Overall & 15,458 & $14.43(14.21-14.66)$ & 13.09 (12.88-13.30) \\
\hline \multicolumn{4}{|l|}{ Age groups (y) } \\
\hline $25-34$ & 460 & $2.00(1.82-2.18)$ & \\
\hline $35-44$ & 1,435 & $7.04(6.68-7.41)$ & - \\
\hline $45-54$ & 3,811 & $18.23(17.65-18.81)$ & - \\
\hline $55-64$ & 5,750 & $28.38(27.65-29.12)$ & - \\
\hline $65-74$ & 3,002 & $21.63(20.86-22.41)$ & - \\
\hline $75-84$ & 841 & $13.12(12.24-14.01)$ & - \\
\hline $85+$ & 159 & $6.97(5.89-8.06)$ & - \\
\hline \multicolumn{4}{|l|}{ Race/ethnicity } \\
\hline White/non-Hispanic & 10,807 & $15.30(15.01-15.59)$ & 13.19 (12.93-13.45) \\
\hline Black/non-Hispanic & 1,087 & $8.80(8.27-9.32)$ & $8.29(7.78-8.80)$ \\
\hline Hispanic & 2,800 & $16.65(16.03-17.26)$ & 19.04 (18.30-19.78) \\
\hline Native American & 477 & 34.57 (31.47-37.68) & $34.11(31.02-37.21)$ \\
\hline \multicolumn{4}{|l|}{ Urbanization } \\
\hline Urban & 12,783 & 13.99 (13.74-14.23) & $12.84(12.61-13.07)$ \\
\hline Rural & 2,675 & $17.05(16.41-17.70)$ & $14.67(14.09-15.26)$ \\
\hline \multicolumn{4}{|l|}{ Region } \\
\hline Northeast & 1,803 & $9.57(9.13-10.01)$ & $8.52(8.12-8.93)$ \\
\hline Midwest & 2,913 & $13.01(12.54-13.48)$ & $11.69(11.25-12.13)$ \\
\hline South & 5,420 & $13.49(13.13-13.85)$ & $12.16(11.83-12.49)$ \\
\hline West & 5,322 & $20.72(20.17-21.28)$ & $19.46(18.93-20.00)$ \\
\hline
\end{tabular}




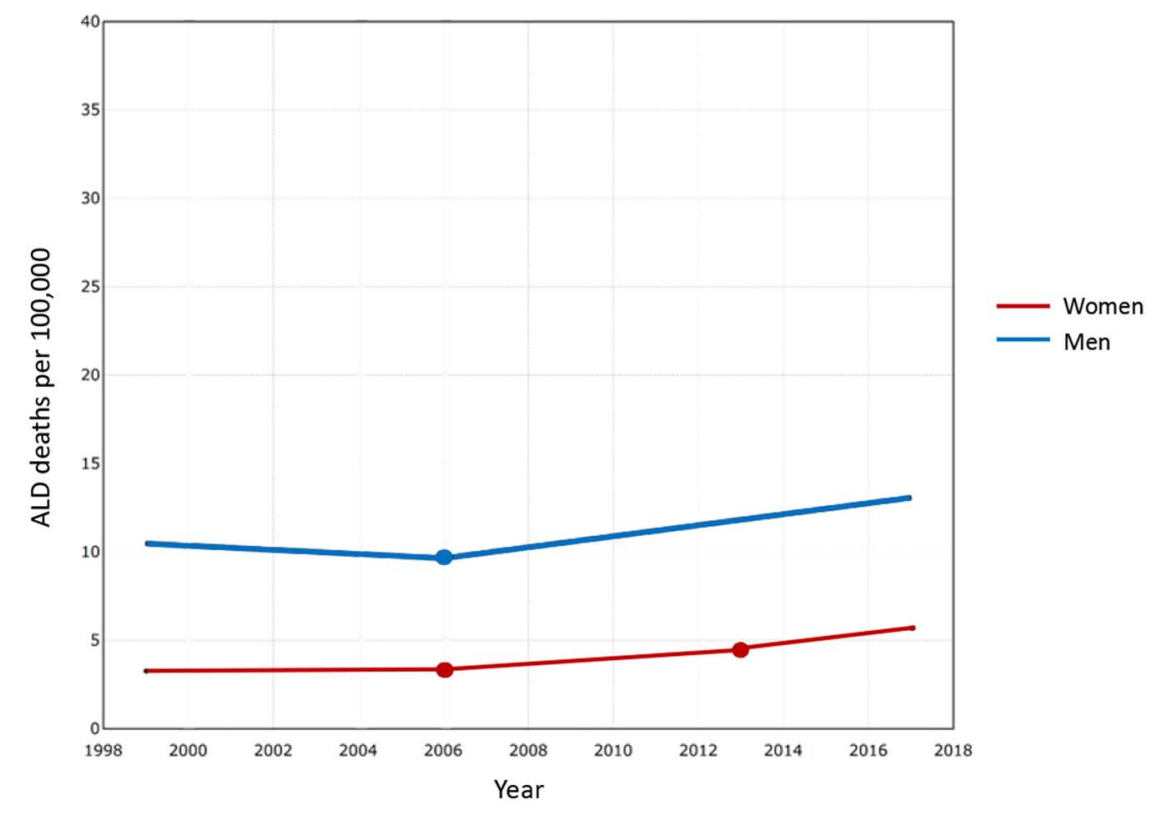

- A significant change in slope (i.e. Joinpoint)

Figure 1. Mortality from ALD in the United States from 1999 to 2017 by sex. Trends in mortality rates and significant changes in slope determined by Joinpoint analysis. ALD, alcohol-associated liver disease.

In men, Native Americans (ARD 0.3, 95\% CI 0.1-0.6, 1999-2017) and white/non-Hispanics (ARD 0.4, 95\% CI 0.3-0.4, 2006-2017) had the largest recent increases in ALD mortality (Figure 3). Conversely, ALD death rates decreased in black/nonHispanics by 0.7 per 100,000 ( $95 \%$ CI -0.9 to -0.5$)$ from 1999 to 2006 and was stable (ARD 0.0, 95\% CI 0.0-0.2) from 2006 to 2017.

\section{Mortality from ALD higher and increasing disproportionately in rural areas}

In 2017, age-adjusted ALD mortality was higher in rural compared with urban inhabitants (6.5 vs 5.4/100,000 in women and 14.7 vs $12.8 / 100,000$ in men). The West region had the highest ALD death rate in 2017 with 8.9/100,000 (95\% CI 8.5-9.3) in women and 19.5/100,000 (95\% CI 18.9-20.0) in men.

In women, the annual rise in ALD mortality was also higher in rural areas (ARD 0.4, 95\% CI 0.3-0.6, 2013-2017) compared with urban areas (ARD 0.2, 95\% CI 0.2-0.3, 2008-2017). Similar trends were seen in men with a 0.8 per 100,000 yearly increase in ALD mortality rates in rural areas. The largest regional increases were seen in Midwestern women (2013-2017 ARD 0.4, 95\% CI 0.2-0.7) and men (2011-2017 ARD 0.4, 95\% CI 0.3-0.5) and men from the South (2011-2017 ARD 0.5, 95\% CI 0.4-0.6). Annual mortality rates in men and women and all demographic subcategories are detailed in the supplemental tables (see Supplementary Digital Content 2, http://links.lww.com/AJG/B306).

\section{DISCUSSION}

Life expectancy in the United States is decreasing in large part due to an epidemic of addiction (1). Our results highlight the large and growing role of ALD in these concerning trends and identify subpopulations at highest risk of ALD mortality who may benefit from targeted public health interventions. ALD mortality is particularly high and increasing in middle-aged men and women, Native Americans, non-Hispanic whites, and those living in rural areas. Increases in ALD mortality rates are seen in almost every age and race/ethnicity since 2006 , which may be due to increased alcohol use during times of economic uncertainty that proceeded the US recession of 2008 (17-20).

Worldwide, alcohol use ranks seventh in risk factors that lead to death and disability, accounting for 2.8 million deaths annually (21). In the United States, AUD accounts for more years lived with disability than dementia or asthma (22). Recent publications have reported increased mortality in the United States from chronic liver disease and cirrhosis, including ALD (2,7,8). Although 1 study reported on the increasing relative risk of ALD mortality in Americans aged 24-34 years, our study is focused on the burden of ALD from a population health perspective, i.e., the underlying risks by presenting ARDs (8). Our work highlights important disparities in the risk of ALD mortality by sex, age, and race. Specifically, the underlying risk is higher in men compared with women, and the risks are higher in middle-aged and older age groups. With regard to patterns over time, the growing risk with the greatest population health impact is occurring in both men and women who are middle aged and older. As has been pointed out previously, increasing ALD mortality mirrors declines seen in mental health and ability to work and increases in suicides and drug overdoses seen in middle-aged Americans (2). Although these trends preceded the economic downturn in the first decade of the 21st century, they may be related to financial insecurity prior to the recession.

ALD mortality and recent rate increases were particularly marked among Native Americans. Given these trends, studying ALD in this underserved population should be high priority. Compared with whites, Native Americans had 2 times the ALD mortality in 2017 and, in women, 2 times higher annual mortality rate increases, indicative of a public health crisis in this population. There are several potential explanations for these strikingly high mortality figures in Native Americans. First, levels of alcohol use or 
Table 3. Trends in mortality from ALD among women in the United States, 1999-2017

\begin{tabular}{|c|c|c|c|c|c|c|c|c|c|c|}
\hline & \multicolumn{3}{|c|}{ Trend 1} & \multicolumn{3}{|c|}{ Trend 2} & \multicolumn{3}{|c|}{ Trend 3} & \multirow[b]{2}{*}{ AAPC (1999-2017) } \\
\hline & Years & ARD $(95 \% \mathrm{Cl})$ & $\operatorname{APC}(95 \% \mathrm{Cl})$ & Years & ARD $(95 \% \mathrm{Cl})$ & APC $(95 \% \mathrm{Cl})$ & Years & ARD $(95 \% \mathrm{Cl})$ & APC $(95 \% \mathrm{Cl})$ & \\
\hline Overall & 1999-2006 & 0.01 ( -0.01 to 0.04$)$ & 0.00 ( -1.07 to 1.09$)$ & $2006-2013$ & $0.16^{\mathrm{a}}$ (0.13 to 0.19$)$ & $3.98^{\mathrm{a}}$ (3.20 to 4.78$)$ & 2013-2017 & $0.30^{\mathrm{a}}$ (0.23 to 0.37$)$ & $6.02^{\mathrm{a}}(4.45$ to 7.60$)$ & $3.08^{\mathrm{a}}$ (2.54 to 3.63 ) \\
\hline \multicolumn{11}{|l|}{ Age groups (y) } \\
\hline $25-34$ & 1999-2003 & $-0.05^{a}(-0.08$ to -0.01$)$ & $-7.77(-15.42$ to 0.58$)$ & 2003-2009 & $0.04^{\mathrm{a}}$ (0.02 to 0.07 ) & $13.27^{\mathrm{a}}$ (10.21 to 16.40$)$ & 2009-2017 & $0.10^{\mathrm{a}}$ (0.09 to 0.12 ) & 7.58 ( -3.25 to 19.63$)$ & $6.07^{\mathrm{a}}$ (2.95 to 9.28 ) \\
\hline $35-44$ & 1999-2012 & -0.01 ( -0.03 to 0.01$)$ & $-0.17(-0.89$ to 0.55$)$ & 2012-2017 & $0.27^{\mathrm{a}}$ (0.18 to 0.37$)$ & $8.18^{\mathrm{a}}$ (5.08 to 11.38$)$ & & & & $2.08^{\mathrm{a}}$ (1.19 to 2.98$)$ \\
\hline $45-54$ & 1999-2005 & $0.16^{\mathrm{a}}$ (0.05 to 0.28$)$ & $2.65^{\mathrm{a}}$ (0.26 to 5.09$)$ & 2005-2017 & $0.33^{\mathrm{a}}$ (0.28 to 0.37$)$ & $4.33^{\mathrm{a}}$ (2.91 to 5.76$)$ & & & & $3.76^{\mathrm{a}}$ (2.58 to 4.96$)$ \\
\hline $55-64$ & 1999-2008 & $0.06(-0.03$ to 0.14$)$ & 0.68 ( -1.10 to 2.49$)$ & $2008-2017$ & $0.55^{\mathrm{a}}$ (0.47 to 0.64$)$ & $6.86^{\mathrm{a}}(5.91$ to 7.81$)$ & & & & $4.06^{\mathrm{a}}$ (3.18 to 4.96$)$ \\
\hline 65-74 & 1999-2011 & $-0.02(-0.06$ to 0.02$)$ & $-0.31(-1.27$ to 0.66$)$ & 2011-2017 & $0.31^{\mathrm{a}}(0.2$ to 0.42$)$ & $6.19^{\mathrm{a}}$ (3.93 to 8.50 ) & & & & $1.81^{\mathrm{a}}$ (0.92 to 2.71$)$ \\
\hline $75-84$ & 1999-2017 & $0.01(-0.02$ to 0.03$)$ & $0.15(-0.68$ to 0.99$)$ & & & & & & & $0.15(-0.68$ to 0.99$)$ \\
\hline $85+$ & 1999-2010 & $-0.02(-0.05$ to 0.00$)$ & $-2.30(-5.09$ to 0.57$)$ & 2010-2017 & $0.09^{\mathrm{a}}$ (0.03 to 0.14 ) & $7.34^{\mathrm{a}}$ (2.18 to 12.75 ) & & & & $1.34(-1.05$ to 3.78$)$ \\
\hline \multicolumn{11}{|l|}{ Race/ethnicity } \\
\hline $\begin{array}{l}\text { White/non- } \\
\text { Hispanic }\end{array}$ & 1999-2006 & $0.06^{a}$ (0.03 to 0.09$)$ & $1.90^{\mathrm{a}}$ (0.97 to 2.84$)$ & $2006-2013$ & $0.19^{\mathrm{a}}$ (0.16 to 0.23 ) & $4.74^{a}$ (3.68 to 5.81 ) & 2013-2017 & $0.39^{\mathrm{a}}$ (0.31 to 0.47$)$ & $6.92^{\mathrm{a}}(5.18$ to 8.68$)$ & $4.10^{\mathrm{a}}$ (3.51 to 4.70 ) \\
\hline $\begin{array}{l}\text { Black/non- } \\
\text { Hispanic }\end{array}$ & 1999-2006 & $-0.25^{a}(-0.33$ to -0.17$)$ & $-7.19^{a}(-9.35$ to -4.98$)$ & $2006-2017$ & $0.10^{\mathrm{a}}$ (0.07 to 0.13 ) & $3.20^{\mathrm{a}}$ (2.02 to 4.38 ) & & & & $-0.97(-2.01$ to 0.07$)$ \\
\hline Hispanic & 1999-2005 & $-0.06(-0.17$ to 0.05$)$ & -1.64 ( -5.09 to 1.93$)$ & 2005-2017 & $0.11^{\mathrm{a}}$ (0.08 to 0.14$)$ & $3.02^{\mathrm{a}}$ (2.09 to 3.95$)$ & & & & $1.44^{\mathrm{a}}$ (0.21 to 2.68$)$ \\
\hline Native American & 1999-2005 & -0.14 ( -0.61 to 0.32 ) & $-1.18(-5.34$ to 3.16$)$ & 2005-2017 & $0.76^{\mathrm{a}}$ (0.61 to 0.91$)$ & $3.54^{\mathrm{a}}$ (2.74 to 4.34 ) & & & & $2.21^{a}$ (0.98 to 3.44$)$ \\
\hline \multicolumn{11}{|l|}{ Urbanization } \\
\hline Urban & 1999-2008 & 0.03 (0.00 to 0.05$)$ & $-0.00(-1.15$ to 1.15$)$ & 2008-2017 & $0.22^{\mathrm{a}}$ (0.19 to 0.25$)$ & $4.60^{\mathrm{a}}$ (4.10 to 5.09 ) & & & & $2.78^{\mathrm{a}}$ (2.28 to 3.29 ) \\
\hline Rural & 1999-2003 & $0.04(-0.08$ to 0.15$)$ & $0.55(-5.71$ to 7.23$)$ & 2003-2013 & $0.17^{\mathrm{a}}(0.13$ to 0.21$)$ & $4.14^{\mathrm{a}}$ (3.23 to 5.07 ) & 2013-2017 & $0.44^{\mathrm{a}}(0.28$ to 0.60$)$ & $7.58^{\mathrm{a}}$ (4.38 to 10.88$)$ & $4.29^{\mathrm{a}}$ (3.02 to 5.57 ) \\
\hline \multicolumn{11}{|l|}{ Region } \\
\hline Northeast & 1999-2006 & $-0.04(-0.09$ to 0.01$)$ & $-1.39(-3.31$ to 0.57$)$ & $2006-2017$ & $0.13^{\mathrm{a}}(0.11$ to 0.16$)$ & $4.96^{\mathrm{a}}$ (4.07 to 5.87 ) & & & & $2.44^{\mathrm{a}}$ (1.58 to 3.32 ) \\
\hline Midwest & 1999-2007 & $0.07^{\mathrm{a}}(0.03$ to 0.10$)$ & $1.61(-1.91$ to 5.25$)$ & 2007-2014 & $0.18^{\mathrm{a}}$ (0.11 to 0.24$)$ & $4.28^{\mathrm{a}}(2.76$ to 5.81$)$ & 2014-2017 & $0.43^{\mathrm{a}}(0.21$ to 0.65$)$ & $8.28^{\mathrm{a}}$ (4.50 to 12.19 ) & $4.40^{\mathrm{a}}$ (3.05 to 5.76 ) \\
\hline South & 1999-2009 & $0.00(-0.03$ to 0.04$)$ & -0.25 ( -1.71 to 1.24$)$ & 2009-2017 & $0.22^{\mathrm{a}}$ (0.17 to 0.27 ) & $5.94^{\mathrm{a}}$ (4.68 to 7.22$)$ & & & & $2.80^{\mathrm{a}}$ (1.91 to 3.70 ) \\
\hline West & 1999-2005 & $0.01(-0.10$ to 0.13$)$ & 0.54 ( -1.69 to 2.83 ) & 2005-2017 & $0.27^{\mathrm{a}}(0.22$ to 0.31$)$ & $3.66^{\mathrm{a}}$ (3.01 to 4.32 ) & & & & $2.61^{\mathrm{a}}$ (1.81 to 3.42 ) \\
\hline
\end{tabular}


Table 4. Trends in mortality from ALD among men in the United States, 1999-2017

\begin{tabular}{|c|c|c|c|c|c|c|c|c|c|c|}
\hline & \multicolumn{3}{|c|}{ Trend 1} & \multicolumn{3}{|c|}{ Trend 2} & \multicolumn{3}{|c|}{ Trend 3} & \multirow[b]{2}{*}{ AAPC (1999-2017) } \\
\hline & Years & ARD $(95 \% \mathrm{Cl})$ & APC $(95 \% \mathrm{Cl})$ & Years & ARD $(95 \% \mathrm{Cl})$ & APC $(95 \% \mathrm{Cl})$ & Years & ARD $(95 \% \mathrm{Cl})$ & $\operatorname{APC}(95 \% \mathrm{Cl})$ & \\
\hline Overall & 1999-2006 & $-0.12^{\mathrm{a}}(-0.22$ to -0.02$)$ & $-1.64^{\mathrm{a}}(-2.87$ to -0.39$)$ & 2006-2017 & $0.31^{\mathrm{a}}(0.26$ to 0.36$)$ & $2.66^{\mathrm{a}}$ (2.27 to 3.05$)$ & & & & $1.12^{\mathrm{a}}$ (0.75 to 1.66$)$ \\
\hline \multicolumn{11}{|l|}{ Age groups (y) } \\
\hline $25-34$ & 1999-2010 & $0.02^{\mathrm{a}}$ (0.00 to 0.04$)$ & -0.36 ( -4.32 to 3.75$)$ & 2010-2017 & $0.16^{\mathrm{a}}(0.11$ to 0.20$)$ & $8.49^{\mathrm{a}}$ (6.83 to 10.17$)$ & & & & $4.95^{a}$ (3.21 to 6.73 ) \\
\hline $35-44$ & 1999-2005 & $-0.23^{\mathrm{a}}(-0.34$ to -0.13$)$ & $-3.74^{\mathrm{a}}(-5.51$ to -1.95$)$ & $2005-2013$ & 0.05 ( -0.03 to 0.13$)$ & 0.89 ( -0.72 to 2.53 ) & 2013-2017 & $0.30^{\mathrm{a}}(0.09-0.51)$ & $4.78^{\mathrm{a}}$ (1.08 to 8.61$)$ & 0.16 ( -0.94 to 1.27$)$ \\
\hline $45-54$ & 1999-2004 & $-0.12(-0.35$ to 0.11$)$ & $-0.69(-2.26$ to 0.90$)$ & 2004-2017 & $0.22^{\mathrm{a}}(0.17$ to 0.28$)$ & $1.31^{\mathrm{a}}(0.96$ to 1.66$)$ & & & & $0.75^{\mathrm{a}}$ (0.28 to 1.21$)$ \\
\hline $55-64$ & 1999-2004 & $-0.31^{\mathrm{a}}(-0.62$ to -0.01$)$ & $-1.14(-2.85$ to 0.61$)$ & 2004-2017 & $0.86^{\mathrm{a}}$ (0.79 to 0.92$)$ & $3.79^{\mathrm{a}}$ (3.47 to 4.12 ) & & & & $2.40^{\mathrm{a}}$ (1.90 to 2.90$)$ \\
\hline $65-74$ & 1999-2003 & $-0.54^{\mathrm{a}}(-0.98$ to -0.1$)$ & $-3.23^{\mathrm{a}}(-6.07$ to -0.30$)$ & 2003 to 2012 & $0.08(-0.06$ to 0.22$)$ & 0.57 ( -0.43 to 1.57$)$ & 2012-2017 & $1.09^{\mathrm{a}}$ (0.83 to 1.36 ) & $5.90^{\mathrm{a}}$ (4.22 to 7.61$)$ & $1.15^{\mathrm{a}}$ (0.31 to 2.00$)$ \\
\hline $75-84$ & 1999-2009 & $-0.11^{\mathrm{a}}(-0.22$ to -0.01$)$ & $-1.11^{\mathrm{a}}(-2.14$ to -0.05$)$ & 2009-2017 & $0.45^{\mathrm{a}}(0.31$ to 0.60$)$ & $4.13^{\mathrm{a}}(2.77$ to 5.51$)$ & & & & $1.19^{\mathrm{a}}$ (0.42 to 1.96$)$ \\
\hline $85+$ & 1999-2003 & $-0.33^{a}(-0.64$ to -0.02$)$ & $-5.64(-11.50$ to 0.60$)$ & 2003-2013 & $0.06(-0.02$ to 0.13$)$ & 0.96 ( -0.73 to 2.69 ) & 2013-2017 & $0.48^{\mathrm{a}}(0.23$ to 0.72$)$ & $8.30^{\mathrm{a}}$ (3.52 to 13.30$)$ & $1.02(-0.75$ to 2.82$)$ \\
\hline \multicolumn{11}{|l|}{ Race/ethnicity } \\
\hline $\begin{array}{l}\text { White/non- } \\
\text { Hispanic }\end{array}$ & 1999-2006 & $-0.02(-0.11$ to 0.07$)$ & -0.62 ( -1.89 to 0.67$)$ & $2006-2017$ & $0.36^{\mathrm{a}}(0.31$ to 0.41$)$ & $3.19^{\mathrm{a}}$ (2.79 to 3.60$)$ & & & & $1.91^{\mathrm{a}}$ (1.44 to 2.38 ) \\
\hline $\begin{array}{l}\text { Black/non- } \\
\text { Hispanic }\end{array}$ & 1999-2006 & $-0.67^{\mathrm{a}}(-0.88$ to -0.46$)$ & $-6.99^{\mathrm{a}}(-8.99$ to -4.93$)$ & $2006-2017$ & $0.07(-0.01$ to 0.15$)$ & 0.78 ( -0.30 to 1.87$)$ & & & & $-2.32^{\mathrm{a}}(-3.27$ to -1.35$)$ \\
\hline Hispanic & 1999-2004 & $-0.96^{\mathrm{a}}(-1.52$ to -0.40$)$ & $-4.84^{\mathrm{a}}(-7.74$ to -1.84$)$ & 2004-2017 & $0.14^{\mathrm{a}}$ (0.04 to 0.24$)$ & $0.75^{\mathrm{a}}$ (0.16 to 1.34$)$ & & & & -0.84 ( -1.70 to 0.04$)$ \\
\hline $\begin{array}{l}\text { Native } \\
\text { American }\end{array}$ & 1999-2017 & $0.32^{\mathrm{a}}$ (0.09 to 0.56$)$ & $1.08^{\mathrm{a}}$ (0.30 to 1.87$)$ & & & & & & & $1.08^{\mathrm{a}}$ (0.30 to 1.87$)$ \\
\hline \multicolumn{11}{|l|}{ Urbanization } \\
\hline Urban & 1999-2005 & $-0.20^{\mathrm{a}}(-0.32$ to -0.08$)$ & $-1.85^{a}(-3.05$ to -0.63$)$ & 2005-2017 & $0.27^{\mathrm{a}}(0.23$ to 0.31$)$ & $2.50^{\mathrm{a}}$ (2.12 to 2.88$)$ & & & & $1.03^{\mathrm{a}}$ (0.59 to 1.48$)$ \\
\hline Rural & 1999-2002 & -0.36 ( -0.90 to 0.18$)$ & $-3.45(-9.23$ to 2.70$)$ & 2002-2013 & $0.24^{\mathrm{a}}(0.16$ to 0.33$)$ & $2.36^{\mathrm{a}}$ (1.46 to 3.27$)$ & 2013-2017 & $0.75^{\mathrm{a}}$ (0.37 to 1.12 ) & $5.62^{\mathrm{a}}(2.35$ to 9.01$)$ & $2.08^{\mathrm{a}}$ (0.85 to 3.32) \\
\hline \multicolumn{11}{|l|}{ Region } \\
\hline Northeast & 1999-2005 & $-0.20^{\mathrm{a}}(-0.32$ to -0.09$)$ & $-2.73^{\mathrm{a}}(-4.38$ to -1.06$)$ & 2005-2017 & $0.19^{\mathrm{a}}(0.15$ to 0.23$)$ & $2.52^{\mathrm{a}}$ (1.96 to 3.08$)$ & & & & $0.74^{\mathrm{a}}$ (0.12 to 1.36$)$ \\
\hline Midwest & 1999-2002 & $-0.29(-0.57$ to -0.01$)$ & $-3.49(-7.04$ to 0.19$)$ & 2002-2011 & $0.18^{\mathrm{a}}(0.12$ to 0.24$)$ & $2.18^{\mathrm{a}}$ (1.39 to 2.97$)$ & 2011-2017 & $0.44^{\mathrm{a}}$ (0.34 to 0.54$)$ & $4.24^{\mathrm{a}}$ (3.18 to 5.32) & $1.89^{\mathrm{a}}$ (1.16 to 2.63 ) \\
\hline South & 1999-2004 & $-0.27^{\mathrm{a}}(-0.42$ to -0.12$)$ & $-2.89^{\mathrm{a}}(-4.57$ to -1.18$)$ & 2004-2011 & $0.07(-0.03$ to 0.17$)$ & 0.81 ( -0.45 to 2.08 ) & 2011-2017 & $0.51^{\mathrm{a}}(0.40$ to 0.61$)$ & $4.86^{\mathrm{a}}$ (3.75 to 5.99) & $1.09^{\mathrm{a}}$ (0.39 to 1.79 ) \\
\hline West & 1999-2004 & $-0.17(-0.48$ to 0.14$)$ & $-0.92(-3.00$ to 1.20$)$ & 2004-2017 & $0.32^{\mathrm{a}}(0.25$ to 0.39$)$ & $1.80^{\mathrm{a}}$ (1.37 to 2.24$)$ & & & & $1.04^{\mathrm{a}}(0.43$ to 1.65$)$ \\
\hline
\end{tabular}



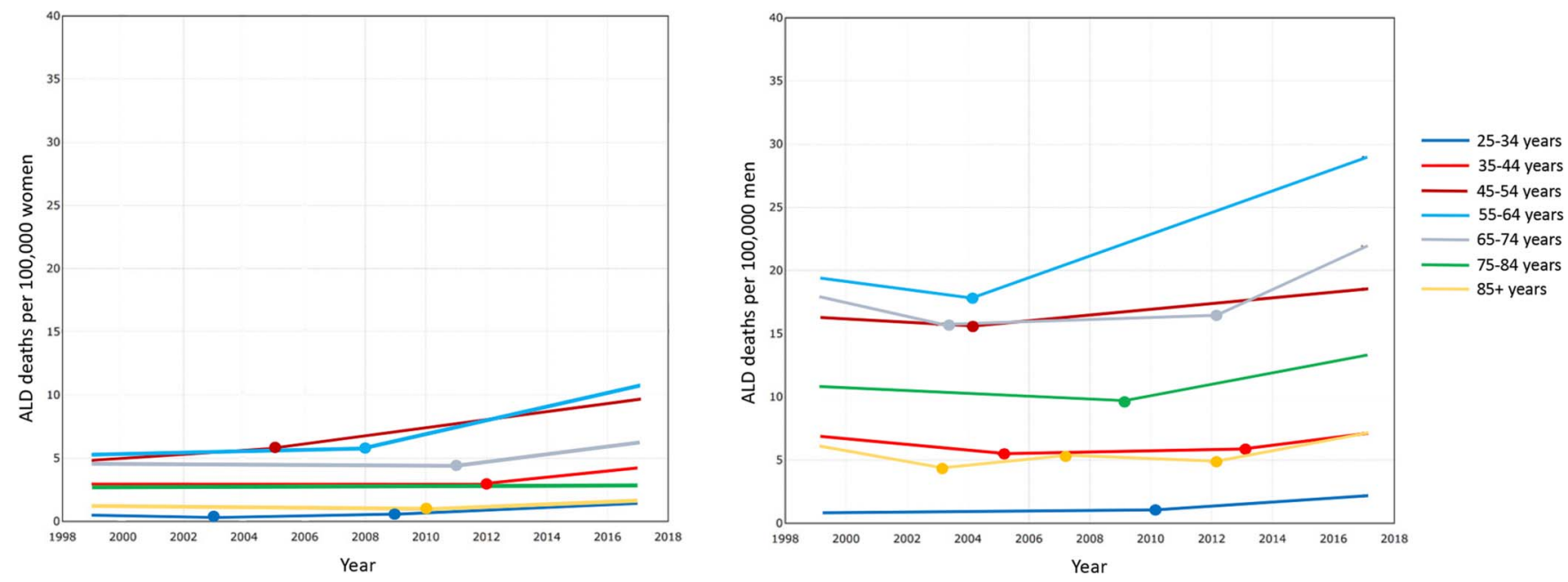

- A significant change in slope (i.e. Joinpoint)

Figure 2. Mortality from ALD in the United States from 1999 to 2017 in women (left panel) and men (right panel) by age groups. Trends in mortality rates and significant changes in slope determined by Joinpoint analysis. ALD, alcohol-associated liver disease.

abuse may be higher among Native Americans, although data on alcohol use relative to other groups in this population are conflicting, with lower overall alcohol intake but more prevalent binge drinking in Native American teenagers (23,24). Second, increased mortality may be due to higher susceptibility to ALD in the Native American population. Although small studies have failed to demonstrate a difference in alcohol metabolism or levels of liver alcohol dehydrogenase between whites and Native Americans, there may be undiscovered genetic risk factors among this population (25). Third, Native American populations may have higher levels of concomitant nonalcoholic fatty liver disease or hepatitis $\mathrm{C}$ virus contributing to liver-related complications and deaths in patients with ALD $(26,27)$. Last, it may be that there is increased coding of ALD mortality in this population. However, misclassification is unlikely to account for the outsized burden of ALD mortality we observed in Native Americans.

Although ALD mortality rates were lower among women and nonwhite ethnicities, data on AUD indicate that this may change in the future. The prevalence of AUD continues to increase in the US population with the most pronounced increases among women, nonwhite ethnicities, older adults, and those with lower education and income levels (28). These trends raise concern that mortality from ALD will only continue to increase in the United States, particularly among these at-risk subgroups.

Abstinence from alcohol is the mainstay of treatment for ALD but patient underreporting impedes detection (29). Failure to address comorbid psychiatric comorbidities, which are common in the setting of substance use disorders, also limits detection and treatment (30). The difficulties in screening for AUD and its end-organ manifestations are reinforced by studies showing that less than half of American adults are receiving recommended screening for alcohol misuse and that ALD is diagnosed at a later stage compared with other etiologies of liver disease $(31,32)$. In addition to issues with underdiagnosis, treatments are limited in ALD. Treatment of AUD with
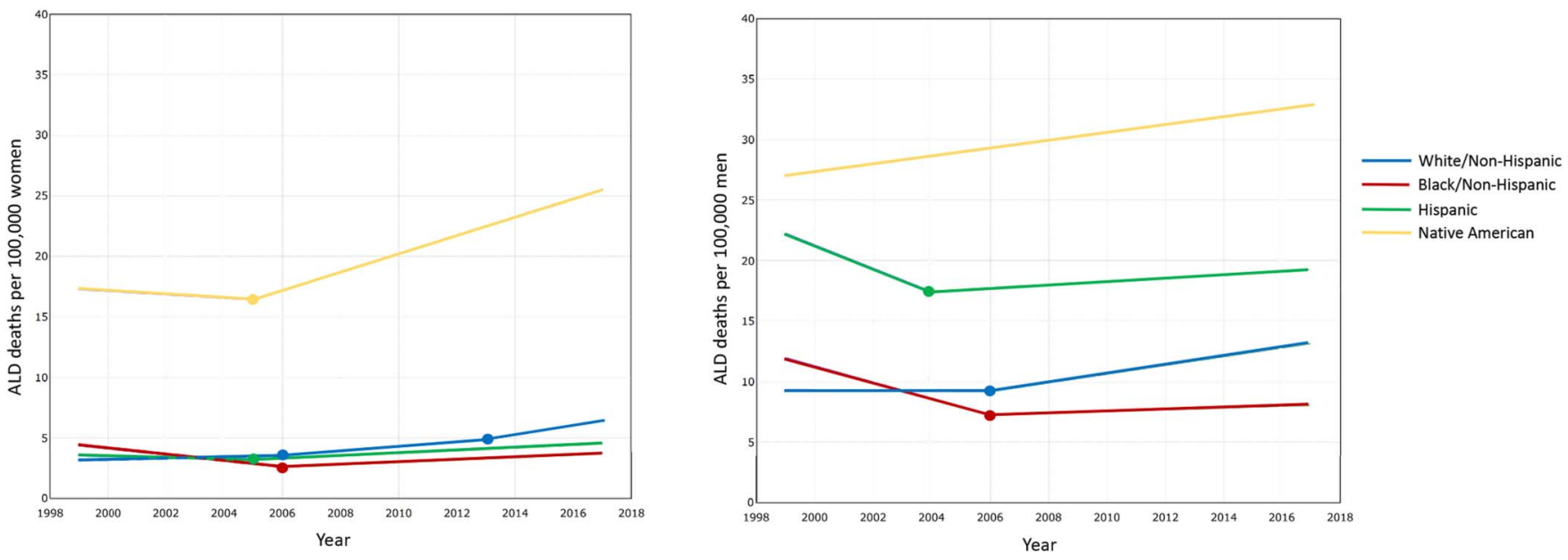

- A significant change in slope (i.e. Joinpoint)

Figure 3. Mortality from ALD in the United States from 1999 to 2017 in women (left panel) and men (right panel) by race/ethnicity. Trends in mortality rates and significant changes in slope determined by Joinpoint analysis. ALD, alcohol-associated liver disease. 
psychosocial interventions is often insufficient, and medications to induce and maintain abstinence have safety concerns or insufficient evidence of efficacy in patients with $\operatorname{ALD}(29,33,34)$. There have been few advances in alcohol-related hepatitis since prednisolone was first recommended in 1971 (35). Last, patients may encounter barriers to addiction treatment, potentially due to the associated societal stigma.

The increase in ALD mortality raises the question of whether we are experiencing a larger epidemic of addiction and self-medication concomitant with increasing rates of opioid misuse. This is suggested by similarities in demographic characteristics of those affected by opioids and ALD, including higher mortality rates in rural areas and non-Hispanic whites (9). There are innovative initiatives in place to address the opioid epidemic; however, alcohol receives far less attention (36). Given the potential for considerable overlap in the burden of alcohol and opioid abuse, it may be possible to leverage resources allocated to address the opioid crisis to simultaneously address AUD.

We have estimated the absolute and changing risk of ALD mortality using population-based data and have stratified by age, sex, and race to generate actionable estimates of the burden of disease. These nationally representative, up-to-date data on the mortality burden of ALD may help guide future public health interventions. However, this analysis has potential limitations. First, our estimates of mortality are based on death certificates, which may be inaccurate (37). We decreased the risk of ascertainment bias by limiting our analysis to the underlying cause of death, thus generating the most conservative estimate possible. Second, our estimates of ALD mortality likely underestimate its true burden because our definition did not capture deaths from hepatocellular carcinoma or liver disease from multiple etiologies (e.g., hepatitis C virus and ALD). This is emphasized by previous studies demonstrating that cirrhosis-related deaths are underestimated (37). We chose to limit our definition to ALD alone to maximize its specificity for identifying liver-related deaths attributable to alcohol use.

In conclusion, mortality from ALD has increased among men and women of almost every age and race in the United States with the exception of non-Hispanic blacks. As such, a comprehensive effort to address ALD mortality in the United States is needed starting with better therapeutic interventions, strategies to address excessive alcohol consumption (e.g., alcohol taxes and dram shop liability), and public health interventions. Given the overlap between populations affected by AUD and opioid abuse, infrastructure being developed to address the opioid epidemic could be leveraged to help address ALD.

\section{CONFLICTS OF INTEREST}

\section{Guarantor of the article: Anne F. Peery, MD, MSCR.}

Specific author contributions: A.M.M. and A.F.P.: study design, statistical analysis and interpretation of data, drafting of the manuscript, and critical revision of the manuscript. J.Y.Y.: statistical analysis and interpretation of the data and critical revision of the manuscript. A.S.B. and R.B.: study design and critical revision of the manuscript.

Financial support: This research was supported in part by grants from the National Institutes of Health, K23DK113225, T32

DK007634, U01AA021908, and U01AA020821.

Potential competing interests: None to report.
Study Highlights

\section{WHAT IS KNOWN}

$\checkmark$ Life expectancy among Americans is decreasing.

Although overshadowed by opioid-related deaths, ALD mortality is high and is contributing to decreasing life expectancy in the United States.

\section{WHAT IS NEW HERE}

ALD mortality rates in the United States were higher in 2017 than any other year since 1999 and are increasing in recent years.

$\checkmark$ Current ALD mortality rates and recent increases are particularly pronounced in middle-aged adults, Native Americans, and non-Hispanic/whites.

$\checkmark$ Public health interventions should be designed to target these high-risk groups.

\section{REFERENCES}

1. National Center for Health Statistics. Health, United States, 2017 With Special Feature on Mortality. U.S. Department of Health and Human Services: Hyattsville, MD, 2018.

2. Case A, Deaton A. Rising morbidity and mortality in midlife among white non-Hispanic Americans in the 21st century. Proc Natl Acad Sci USA 2015;112:15078-83.

3. Dieleman JL, Baral R, Birger M, et al. US spending on personal health care and public health, 1996-2013. JAMA 2016;316:2627-46.

4. Lee BP, Vittinghoff E, Dodge JL, et al. National trends and long-term outcomes of liver transplant for alcohol-associated liver disease in the United States. JAMA Intern Med 2019;179:340-8.

5. Barritt AS IV, Jiang Y, Schmidt M, et al. Charges for alcoholic cirrhosis exceed all other etiologies of cirrhosis combined: A national and state inpatient survey analysis. Dig Dis Sci 2019;64:1460-9.

6. Ndugga N, Lightbourne TG, Javaherian K, et al. Disparities between research attention and burden in liver diseases: Implications on uneven advances in pharmacological therapies in Europe and the USA. BMJ Open 2017;7:e013620.

7. Kim D, Li AA, Gadiparthi C, et al. Changing trends in etiology-based annual mortality from chronic liver disease, from 2007 through 2016. Gastroenterology 2018;155:1154-63.

8. Tapper EB, Parikh ND. Mortality due to cirrhosis and liver cancer in the United States, 1999-2016: Observational study. BMJ 2018;362:k2817.

9. Centers for Disease Control and Prevention. Underlying cause of death 1999-2017 (2019). (https://wonder.cdc.gov/wonder/help/ucd.html\#). Accessed March 16, 2019.

10. Anderson RN, Rosenberg HM. Age standardization of death rates: Implementation of the year 2000 standard. National vital statistics reports : From the Centers for Disease Control and Prevention, National Center for Health Statistics. Natl Vital Stat Syst 1998;47:1-16.

11. Kim HJ, Fay MP, Feuer EJ, et al. Permutation tests for joinpoint regression with applications to cancer rates. Stat Med 2000;19:335-51.

12. White DL, Thrift AP, Kanwal F, et al. Incidence of hepatocellular carcinoma in all 50 United States, from 2000 through 2012. Gastroenterology 2017;152:812-20.e5.

13. Altekruse SF, Henley SJ, Cucinelli JE, et al. Changing hepatocellular carcinoma incidence and liver cancer mortality rates in the United States. Am J Gastroenterol 2014;109:542-53.

14. Hur C, Miller M, Kong CY, et al. Trends in esophageal adenocarcinoma incidence and mortality. Cancer 2013;119:1149-58.

15. Vuik FE, Nieuwenburg SA, Bardou M, et al. Increasing incidence of colorectal cancer in young adults in Europe over the last 25 years. Gut 2019;68:1820-6.

16. Siegel RL, Miller KD, Jemal A. Colorectal cancer mortality rates in adults aged 20 to 54 years in the United States, 1970-2014. JAMA 2017;318:572-4

17. Richman JA, Rospenda KM, Johnson TP, et al. Drinking in the age of the great recession. J Addict Dis 2012;31:158-72.

18. Bor J, Basu S, Coutts A, et al. Alcohol use during the great recession of 2008-2009. Alcohol Alcohol 2013;48:343-8. 
19. Mulia N, Zemore SE, Murphy R, et al. Economic loss and alcohol consumption and problems during the 2008 to 2009 U.S. recession. Alcohol Clin Exp Res 2014;38:1026-34.

20. Brown RL, Richman JA, Rospenda KM. Economic stressors and alcoholrelated outcomes: Exploring gender differences in the mediating role of somatic complaints. J Addict Dis 2014;33:303-13.

21. Collaborators GBDA. Alcohol use and burden for 195 countries and territories, 1990-2016: A systematic analysis for the global burden of disease study 2016. Lancet 2018;392:1015-35.

22. Mokdad AH, Ballestros K, Echko M, et al. The state of US health, 1990-2016: Burden of diseases, injuries, and risk factors among US states. JAMA 2018;319:1444-72.

23. Cunningham JK, Solomon TA, Muramoto ML. Alcohol use among Native Americans compared to whites: Examining the veracity of the "Native American elevated alcohol consumption" belief. Drug Alcohol Depend 2016;160:65-75.

24. Stanley LR, Harness SD, Swaim RC, et al. Rates of substance use of American Indian students in 8th, 10th, and 12th grades living on or near reservations: Update, 2009-2012. Public Health Rep 2014;129:156-63.

25. Bennion LJ, Li TK. Alcohol metabolism in American Indians and whites. Lack of racial differences in metabolic rate and liver alcohol dehydrogenase. N Engl J Med 1976;294:9-13.

26. US Department of Health and Human Services Office of Minority Health. Obesity in American Indians/Alaska Natives (2017). (https:// minorityhealth.hhs.gov/omh/content.aspx?lvl=3\&lvlID =62\&ID=6457). Accessed March 16, 2019.

27. Edlin BR, Eckhardt BJ, Shu MA, et al. Toward a more accurate estimate of the prevalence of hepatitis C in the United States. Hepatology 2015;62: 1353-63.

28. Grant BF, Chou SP, Saha TD, et al. Prevalence of 12-month alcohol use, high-risk drinking, and DSM-IV alcohol use disorder in the United
States, 2001-2002 to 2012-2013: Results from the national epidemiologic survey on alcohol and related conditions. JAMA psychiatry 2017;74:911-23.

29. Caputo F, Agabio R, Vignoli T, et al. Diagnosis and treatment of acute alcohol intoxication and alcohol withdrawal syndrome: Position paper of the Italian society on alcohol. Intern Emerg Med 2019;14:143-60.

30. Bose J, Hedden SL, Lipari RN, et al. Key substance use and mental health indicators in the United States: Results from the 2017 National Survey on Drug Use and Health (HHS Publication No. SMA 18-5068, NSDUH Series H-53) (2018). (https://www.samhsa.gov/data/). Accessed March 3, 2019.

31. Shah ND, Ventura-Cots M, Abraldes JG, et al. Alcohol-related liver disease is rarely detected at early stages compared with liver diseases of other etiologies worldwide. Clin Gastroenterol Hepatol 2019;17: 2320-9.e12.

32. Shafer PR, Borsky A, Ngo-Metzger Q, et al. The practice gap: National estimates of screening and counseling for alcohol, tobacco, and obesity. Ann Fam Med 2019;17:161-3.

33. Dom G, Woinar M, Crunelle CL, et al. Assessing and treating alcohol relapse risk in liver transplantation candidates. Alcohol Alcohol 2015;50: $164-72$.

34. Minozzi S, Saulle R, Rosner S. Baclofen for alcohol use disorder. Cochrane Database Syst Rev 2018;11:CD012557.

35. Singal AK, Bataller R, Ahn J, et al. ACG clinical guideline: Alcoholic liver disease. Am J Gastroenterol 2018;113:175-94.

36. Collins FS, Koroshetz WJ, Volkow ND. Helping to end addiction over the long-term: The research plan for the NIH HEAL initiative. JAMA 2018; 320:129-30.

37. Asrani SK, Larson JJ, Yawn B, et al. Underestimation of liver-related mortality in the United States. Gastroenterology 2013;145:375-82 e1-2. 